Paralysis

\section{An atypical case of periodic paralysis}

\section{H Mohammed, R V Bhat}

Answers on $p 108$.

A 38 year old man presented with a history of episodic lower limb weakness lasting a few hours. The weakness was predominantly proximal and was preceded by cramps in the affected muscles. There were two such attacks separated by a one month period. He was perfectly normal in between the episodes. The weakness was unrelated to exertion or meals. The upper limbs, eyes, face, tongue, pharynx, larynx, diaphragm, and sphincters were spared. There were no sensory abnormalities. He did not have vomiting or diarrhoea, nor was he on any medication. He had had no major illness in the past. No other family member had a similar illness. His appetite was good and there was no change in his weight in recent years. His sleep was normal, so were his bowel and bladder habits. He did not have any addictions. On physical examination, the patient was afebrile and nervous. He had a heart rate of 120 beats/min and a blood pressure of 170/70 mm Hg.

During the attack, there was a flaccid paraparesis with depressed tendon jerks. In the interattack period, strength was normal and the reflexes were brisk. His serum potassium concentration during the attack was $3.2 \mathrm{mmol} / \mathrm{l}$, and after recovery $4.0 \mathrm{mmol} / \mathrm{l}$ (reference range $3.5-5.0 \mathrm{mmol} / \mathrm{l})$. The concentration in urine was normal. Other electrolyte values were within normal limits. Further studies were performed to establish the aetiology.

\section{QUESTIONS}

(1) What is the diagnosis?

(2) How did we confirm it?

(3) How should the patient be managed? Postgrad Med J 2002;78:101

\section{Authors' affiliations}

I H Mohammed, R V Bhat, Department of Medicine, Kasturba Medical College, Mangalore 575001 , India

Correspondence to: Dr Mohammed; ismohammed@hotmail.com

Submitted 14 March 2001

Accepted 23 April 2001

R Mittal, V Gupta, Department of

Orthopaedics, All India Institute of Medical

Sciences, Ansari Nagar, New Delhi 110 029, India

Correspondence to: Dr Mittal

Submitted 19 January 2001

Accepted 27 March 2001

\title{
Swollen and stiff shoulder
}

\section{R Mittal, V Gupta}

Answers on $\mathrm{p} 108$.

\section{Authors' affiliations}

R Mittal, V Gupta, Department of

Orthopaedics, All India Institute of Medical Sciences, Ansari Nagar, New Delhi 110 029, India

\section{Correspondence to: Dr Mittal}

Submitted 19 January 2001

Accepted 27 March 2001

A 50 year old women was admitted with complaints of swelling and stiffness of right shoulder for three months. There was no history of trauma, fever, or any local injections. She did not drink alcohol and there was no history of any steroid intake. There was no past history of diabetes or syphilis. The swelling was minimally painful and only extremes of shoulder movements were painful. The swelling was fluctuant. There was no neurological deficit. Radiographic examination of the shoulder was done (fig 1) followed by magnetic resonance imaging (MRI) of the cervical spine (fig 2).

\section{QUESTIONS}

(1) What are the pathological changes seen in the radiograph?

(2) What are the pathological changes seen in the MRI scan?

Postgrad Med J 2002;78:101

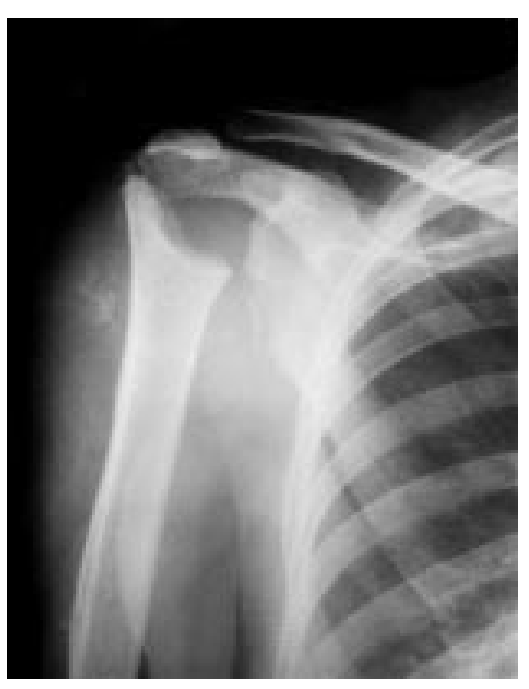

Figure 1 Radiograph of shoulder.

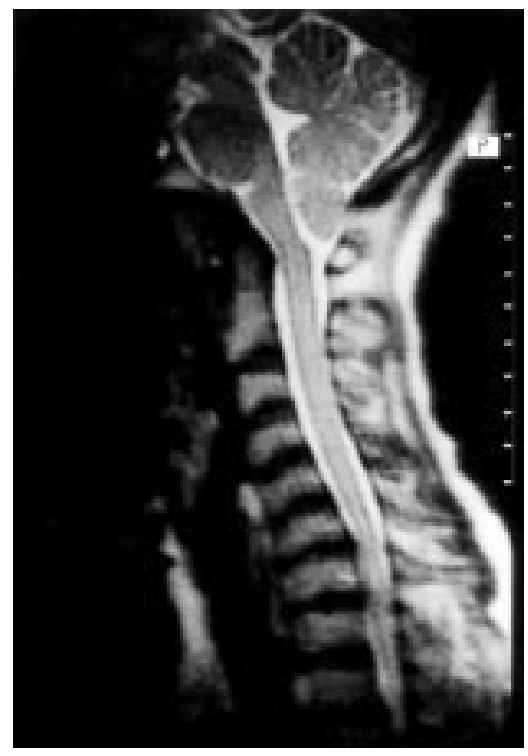

Figure 2 MRI of the cervical spine. 